\title{
Do bactisealventriculostomy catheters have a low rate of ventriculitis and catheter colonization in clinical practice?
}

\author{
Roger Strachan*, Himanshu Shekhar, Shuhaib Dambatta, Pratipal Kalsi \\ From 54th Annual Meeting of the Society for Research into Hydrocephalus and Spina Bifida \\ Vancouver, Canada. 7-10 July 2010
}

\section{Background}

While Bactiseal catheters have been shown to decrease ventriculo-peritoneal shunt infection rates, similar evidence for external ventricular drains (EVD) is lacking [1]. This retrospective study was undertaken to evaluate whether the introduction of Bactiseal EVD in 2004 has decreased infection rates.

\section{Materials and methods}

One hundred and ten patients had undergone EVD insertions from January 2000 to March 2008. After excluding patients who had died within 5 days of the procedure and also those with pre-existing CSF sepsis, a total of 90 patients (with 119 EVD insertions- 66 Standard, 53 Bactiseal) were included in the study. The practice of sending catheter tips for culture was started with the introduction of Bactiseal drains. The parameters studied were age, sex, ASA score, grade of surgeon, significant medical history, trauma, concurrent surgeries, revisional surgery, peri-operative antibiotic, Bactiseal, tunnelling and duration of drainage. The incidence of external ventricular drain related ventriculitis, catheter tip colonisation and the responsible pathogens were noted.

\section{Results}

Eleven cases of ventriculitis were recorded and the majority were caused by Gram positive bacteria. Both Bactiseal and standard catheters were associated with similar infection rates (Fishers Exact test, $\mathrm{p}=0.53$ ). A significantly longer average length of in-situ stay of ventricular catheters was observed in the cases developing

\footnotetext{
* Correspondence: roger.strachan@stees.nhs.uk
Department of Neurosurgery James Cook University Hospital Marton Road

* Correspondence: roger.strachan@stees.nhs.uk
Department of Neurosurgery James Cook University Hospital Marton Road Middlesbrough TS9 6JE, UK
}

C 2010 Strachan et al; licensee BioMed Central Ltd. This is an open access article distributed under the terms of the Creative Commons Attribution License (http://creativecommons.org/licenses/by/2.0), which permits unrestricted use, distribution, and reproduction in any medium, provided the original work is properly cited. ventriculitis (Kolmogorov-Smirnov test, $\mathrm{p}<0.01$ ). The Bactiseal catheters took longer time to develop infection as compared to Standard catheters. But, this difference was not statistically significant (Kaplan-Meier survival analysis, $\mathrm{p}=0.12$ ). Analysis comparing infection incidence for the rest of the risk factors shows that only revisional surgery was associated with higher infection rates (Fishers Exact test, $\mathrm{p}=0.03$ ). Twenty sixBactiseal catheter tips were sent for culture, including catheter tips for 6 cases with ventriculitis. Only 2 catheters were found to be colonised and Pseudomonas was cultured from both (1 with and 1 without associated ventriculitis).

\section{Conclusions}

Ventriculostomy related infections are strongly associated with longer in-situ stay of ventricular catheters. Bactiseal catheters may be the preferred option in those patients needing prolonged ventricular drainage. As compared with historical controls [2], Bactisealventriculostomy catheters have a low rate of colonisation and Pseudomonas seems to be the major culprit. 1. Prevention of infection in neurosurgery: role of "antimicrobial" catheters.

Published: 15 December 2010

\section{References}

1. Bayston R, Ashraf W, Fisher L: Prevention of external ventricular drainrelated ventriculitis. J Hosp Infect. 2007, 65(Suppl 2):39-42.

2. Korinek AM, Reina M, Boch AL, Rivera AO, De Bels D, Puybasset L: Prevention of external ventricular drain-related ventriculitis. Acta Neurochir (Wien) 2005, 147:39-45.

doi:10.1186/1743-8454-7-S1-S41

Cite this article as: Strachan et al:: Do bactisealventriculostomy catheters have a low rate of ventriculitis and catheter colonization in clinical practice? Cerebrospinal Fluid Research 2010 7(Suppl 1):S41. 